\title{
Free-Radical Copolymerization II. Volume Contraction Factors for Some Copolymerization Systems. An Approach Based on Partial Specific Volume
}

\author{
Yung-Dae MA, Takeshi FuKUDA, and Hiroshi INAGAKI \\ Institute for Chemical Research, Kyoto University, \\ Uji, Kycto 611, Japan
}

(Received June 3, 1983)

\begin{abstract}
In order to test the validity of previously developed formulas for the partial molar volume $\tilde{V}_{\mathrm{p}}^{0}$ of a $1-2$ binary copolymer in a mixture of two solvents, density measurements were carried out on styrene-methyl methacrylate and $p$-chlorostyrene-methyl acrylate copolymers dissolved in the relevant monomer(s). The values of the six parameters necessary to compute $\tilde{V}_{\mathrm{p}}{ }^{0}$ were determined for each system, and some comments have been made on the individual parameter values. The predicted values of $\tilde{V}_{\mathrm{p}}^{0}$ were in good agreement with those directly measured. Based on the results, numerical expressions for the volume contraction factors for the low-conversion copolymerizations of the two monomer pairs were derived.
\end{abstract}

KEY WORDS Copolymers in Monomer Mixtures / Partial Specific Volume / Excess Volume of Mixing / Excess Volume of Alternating-Bond Formation / Contraction Factor / Styrene-Methyl Methacrylate / $p$-ChlorostyreneMethyl Acrylate /

There are two general approaches to evaluating the contraction factor $\Gamma$, defined as the volume decrease per unit mole of the monomer(s) converted to the polymer. One is directly measuring the volume vs. conversion curve. This approach is rather tedious, especially for copolymerization systems, and may incur considerable error associated, in particular, with the determination of conversions. The other approach is based on measurements of the partial specific volume(s) of the polymeric species in a relevant (inactive) solution. This approach is indirect but gives more accurate results, provided that density measurements are performed with high precision.

Based on a simple phenomenological method for treating multicomponent systems, we previously ${ }^{1}$ derived new formulas representing the contraction factor $\Gamma$ of a binary-copolymerization system and the partial molar volume $\widetilde{V}_{\mathrm{p}}$ (per monomeric unit) of a copolymer in a mixture of the component monomers. If we denote the polymer and the monomer of kind $\mathrm{A}$ as components 1 and 3, re- spectively, and those of kind $\mathrm{B}$ as components 2 and 4 , respectively, our formulas converge, in the limit of zero polymer concentrations, to ${ }^{1}$

$$
\begin{aligned}
& \hat{V}_{\mathrm{p}}^{0}= \frac{x_{3}\left(F_{1} \tilde{V}_{1,3}^{0}+F_{2} \tilde{V}_{2,3}^{0}\right)+x_{4}\left(F_{1} \tilde{V}_{1,4}^{0}+F_{2} \tilde{V}_{2,4}^{0}\right)}{+F_{12} \Delta V_{12}} \\
& 1+a_{34} x_{3} x_{4} \\
& \Gamma^{0}=\left(F_{1} \Gamma_{1}^{0}+F_{2} \Gamma_{2}^{0}\right)\left(1-a_{34} x_{3} x_{4}\right)-F_{12} \Delta V_{12} \\
&+x_{4} F_{1}\left(a_{34} V_{3}+\tilde{V}_{1,3}^{0}-\tilde{V}_{1,4}^{0}\right) \\
&+x_{3} F_{2}\left(a_{34} V_{4}+\tilde{V}_{2,4}^{0}-\tilde{V}_{2,3}^{0}\right)
\end{aligned}
$$

with

$$
\Gamma_{1}^{0}=V_{3}-\tilde{V}_{1,3}^{0} \quad \text { and } \quad \Gamma_{2}^{0}=V_{4}-\tilde{V}_{2,4}^{0}
$$

where the superscript " 0 " denotes the infinite dilution; $x$ is the volume composition of the monomers before mixing $\left(x_{3}+x_{4}=1\right), F$, the molecomposition of the copolymer $\left(F_{1}+F_{2}=1\right), F_{12}$, the population of the $1-2$ chemical bonds, $\widetilde{V}_{\mathrm{i}, \mathrm{j}}^{0}$, the partial molar volume (per monomeric unit) of 
homopolymer $\mathrm{i}$ in the pure monomer $\mathrm{j}$, and $V_{3}$ and $V_{4}$, the molar volumes of the pure monomers. The parameter $\Delta V_{12}$ is related to the excess volume of the formation of $1-2$ chemical bonds, ${ }^{1}$ while the parameter $a_{34}$ is related to the excess volume in a physical mixing of the two monomers:

$$
v_{\mathrm{s}}=\left(w_{3} v_{3}+w_{4} v_{4}\right)\left(1+a_{34} x_{3} x_{4}\right)
$$

where $v_{\mathrm{s}}$ and $v_{\mathrm{i}}$ are the specific volumes of the monomer mixture and the pure monomer $i$, respectively, and $w_{\mathrm{i}}$, the weight composition of the mixture $\left(\mathrm{i}=3\right.$ or 4 , and $w_{3}+w_{4}=1$ ).

According to eq $2, \Gamma^{0}$ is calculable if the four $\tilde{V}_{\mathrm{i}, \mathrm{j}}^{0}$ 's are known in addition to the two parameters $\Delta V_{12}$ and $a_{34}$. The validity of eq 2 has been confirmed to some extent by testing a certain version of eq 2 with directly measured $\Gamma^{0}$ taken from the literature. ${ }^{1}$ Probably, efforts to make a more critical test of eq 2 along this line is not much rewarding, since it seems difficult to determine $\Gamma^{0}$ with higher precision. For this reason, we attempted to test the validity of eq 1 rather than eq 2 by performing density measurements on styrene (ST)-methylmethacrylate (MMA) and $p$-chlorostyrene $(p C S)$ methyl acrylate (MA) systems. If eq 1 is satisfactory, so should eq 2 be also, since the two equations are based on the same physical model. Numerical values of $\Gamma^{0}$ for the two systems calculated from eq 2 are presented below, along with some comments on their accuracy.

\section{EXPERIMENTAL}

\section{Materials}

Commercially available ST, MMA, MA, and 2$2^{\prime}$-azobisisobutyronitrile (AIBN) were purified accoridng to standard methods. ${ }^{2}$ The monomer $p \mathrm{CS}$ was synthesized and purified as described previously. $^{2}$

\section{Sample Preparation and Characterization}

All the polymerizations, excepting that of MA, were carried out in bulk at $40^{\circ} \mathrm{C}$ with AIBN as the initiator. Polymerization of MA was performed at the same temperature in a $50-\mathrm{vol} \%$ benzene solution with AIBN as the initiator. The methods of polymerization and purification of the polymers are described elsewhere. ${ }^{2}$

The copolymer composition was determined by combustion analysis for carbon. The molecular weights were determined by gel permeation chromatography (GPC). All GPC measurements were carried out at room temperature using reagent grade tetrahydrofuran as a carrier solvent. The column system was calibrated with seven Pressure Chemical Standard Polystyrenes with molecular weights from $4 \times 10^{3}$ to $2.0 \times 10^{6}$ and four anionically synthesized poly(methyl methacrylates) with molecular weights from $2.45 \times 10^{4}$ to $1.59 \times 10^{6}$. The number-average molecular weight $M_{n}$ and the ratio $M_{w} / M_{n}$ of the weight-to-number average molecular weights of the ST-MMA copolymer were estimated on the assumption that the calibration curve for the copolymer is a composition average of those for the parent polymers, while those of the $p$ CS-MA copolymer were estimated by the method described previously. $^{2}$

\section{Density Measurements}

Density measurements were conducted on a $10 \mathrm{ml}$ Weld-type pycnometer at $40^{\circ} \mathrm{C}$, each repeated two or three times. Sample polymers were dried in a vacuum oven for one day, and monomers were redistilled just before preparation of the solutions. A homogeneous solution was obtained by stirring.

\section{RESULTS AND DISCUSSION}

\section{Solvent-Solvent Interaction Parameter $a_{34}$}

The parameter $a_{34}$ defined by eq 4 can be represented in terms of the densities $\rho_{\mathrm{j}}=1 / v_{\mathrm{j}}$ and $\rho_{\mathrm{s}}=1 / v_{\mathrm{s}}$ as

$$
a_{34}=\frac{x_{3} \rho_{3}+x_{4} \rho_{4}-\rho_{\mathrm{s}}}{x_{3} x_{4} \rho_{\mathrm{s}}}
$$

Density data on ST(3)/MMA(4) and $p \mathrm{CS}(3) / \mathrm{MA}(4)$ binary mixtures and the values of $a_{34}$ calculated from eq 5 are presented in Table $I$ and plotted in Figure 1. The data were fitted to the following equation ${ }^{3}$ by using the method of least squares.

$$
a_{34}=A_{0}+A_{1}\left(x_{3}-x_{4}\right)+A_{2}\left(x_{3}-x_{4}\right)^{2}
$$

The ST-MMA system is represented by a linear relation with $A_{0}=-2.9 \times 10^{-3}$ and $A_{1}=$ $-3.2 \times 10^{-3}$, while the $p$ CS-MA system is adequately described by a single constant, $A_{0}=$ $-3.5 \times 10^{-3}$ (full lines in Figure 1). These linear relations reproduce experimental density values within a few units of the fifth decimal place. 
Table I. Densities of monomer mixtures and values of $a_{34}\left(40^{\circ} \mathrm{C}\right)$

\begin{tabular}{ccc} 
& \multicolumn{1}{c}{$\rho_{\mathrm{s}}$} & \\
\cline { 2 - 3 }$w_{3}{ }^{\mathrm{a}}$ & $\mathrm{g} \mathrm{ml}^{-1}$ & $10^{3} a_{34}$ \\
& & \\
\hline $\mathrm{ST} / \mathrm{MMA}$ & & \\
0.00 & $0.9207_{1}$ & - \\
0.23489 & $0.9131_{8}$ & -1.3 \\
0.38616 & $0.9085_{5}$ & -2.4 \\
0.52791 & $0.9041_{7}$ & -3.1 \\
0.68537 & $0.8992_{0}$ & -3.9 \\
0.79239 & $0.8957_{6}$ & -4.8 \\
0.84162 & $0.8941_{2}$ & -5.1 \\
0.90151 & $0.8920_{9}$ & -5.7 \\
1.00 & $0.8885_{9}$ & - \\
$p C S / \mathrm{MA}$ & & \\
0.00 & & - \\
0.17068 & $0.9308_{1}$ & -3.6 \\
0.24288 & $0.9515_{9}$ & -3.5 \\
0.30711 & $0.9605_{9}$ & -3.4 \\
0.44671 & $0.9687_{0}$ & -3.7 \\
0.58716 & $0.9868_{5}$ & -3.8 \\
0.72133 & $1.0056_{7}$ & -3.7 \\
0.85206 & $1.0240_{6}$ & -3.1 \\
0.91356 & $1.0424_{6}$ & -3.2 \\
1.00 & $1.0513_{7}$ & - \\
\hline
\end{tabular}

a Weight composition of ST or $p \mathrm{CS}$.
Partial Specific Volume in Two-Component Systems

The polymerization conditions and molecular characteristics of the polymer samples employed are listed in Table II. Density measurements on polymer/solvent binary mixtures were carried out at relatively low concentrations (below about $0.05 \mathrm{~g} \mathrm{ml}^{-1}$ except for one case), because of the difficulty in handling solutions of higher concentration. The results obtained are presented in Tables III and IV.

The apparent specific volume $v_{\mathrm{p}, \mathrm{j}}^{\mathrm{app}}$ of polymer $\mathrm{p}$ in monomer $j$ ( $p$ denotes either homopolymers 1,2 or a compolymer, and $j$ denotes either monomer 3 or 4) is defined by

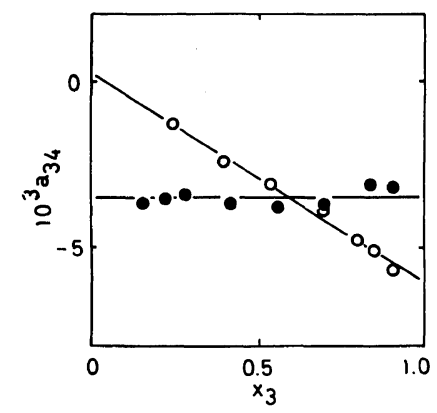

Figure 1. Plots of parameter $a_{34} v s$. volume composition $x_{3}$ for ST(3)/MMA(4) (open circles) and $p \mathrm{CS}(3) / \mathrm{MA}(4)$ (filled circles) binary mixtures at $40^{\circ} \mathrm{C}$.

Table II. Characteristics of polymer samples employed for density measurements

\begin{tabular}{|c|c|c|c|c|c|c|c|}
\hline Sample & $f^{\mathrm{a}}$ & $10^{2} I^{\mathrm{b}}$ & $Y^{\mathrm{c}}$ & $F_{1}^{\mathrm{d}}$ & $F_{12}^{\mathrm{e}}$ & $10^{5}\left(M_{n}\right)_{\mathrm{GPC}}$ & $\left(M_{w} / M_{n}\right)_{\mathrm{GPC}}$ \\
\hline \multicolumn{8}{|c|}{ ST-MMA System } \\
\hline PMMA & 0.00 & 2.136 & 8.84 & 0.00 & 0.00 & 6.64 & 1.86 \\
\hline SM1 & 0.191 & 1.804 & 13.26 & 0.266 & 0.477 & 3.15 & 1.82 \\
\hline SM2 & 0.555 & 1.893 & 3.53 & 0.542 & 0.664 & 2.85 & 1.72 \\
\hline SM3 & 0.788 & 1.760 & 3.40 & 0.727 & 0.487 & 2.29 & 1.68 \\
\hline PST & 1.00 & 1.845 & 7.71 & 1.00 & 0.00 & 2.47 & 1.65 \\
\hline \multicolumn{8}{|c|}{$p$ CS-MA System } \\
\hline $\mathrm{PMA}^{\mathrm{f}}$ & 0.00 & 1.505 & - & 0.00 & 0.00 & 2.80 & 3.15 \\
\hline CMS1 & 0.230 & 3.716 & 8.23 & 0.516 & 0.704 & 1.82 & 1.68 \\
\hline CSM2 & 0.536 & 4.163 & 14.68 & 0.680 & 0.569 & 0.99 & 2.16 \\
\hline CSM3 & 0.712 & 3.819 & 11.00 & 0.818 & 0.348 & 0.91 & 1.78 \\
\hline $\mathrm{P} p \mathrm{CS}$ & 1.00 & 4.124 & 7.56 & 1.00 & 0.00 & 1.44 & 1.52 \\
\hline
\end{tabular}

a Mole fraction of ST or $p$ CS in feed.

b AIBN concentration $\left(\mathrm{moll}^{-1}\right)$.

c Conversion (wt $\%$ ).

d Mole fraction of ST or $p$ CS in copolymer.

e The average population of alternating diads calculated using the terminal-model parameters.

${ }^{f}$ Polymerization was performed in a $50-\mathrm{vol} \%$ benzene solution. 
Table III. Densities of two-component solutions (ST-MMA systems, $40^{\circ} \mathrm{C}$ )

\begin{tabular}{|c|c|c|}
\hline \multirow{2}{*}{$w_{\mathrm{p}}$} & \multirow{2}{*}{$\frac{\rho}{\mathrm{g} \mathrm{ml}^{-1}}$} & \multirow{2}{*}{$\frac{10^{5} \Delta \rho}{\mathrm{g} \mathrm{ml}^{-1}}$} \\
\hline & & \\
\hline \multicolumn{3}{|c|}{ Polymer: PST/Monomer : ST } \\
\hline 0.00 & $0.8885_{9}$ & +2 \\
\hline 0.01119 & 0.8903 & -2 \\
\hline 0.02049 & 0.8918 & +2 \\
\hline 0.02896 & 0.8931 & -2 \\
\hline 0.03957 & 0.8948 & 0 \\
\hline 0.04520 & 0.8956 & -9 \\
\hline 0.05051 & 0.8965 & -3 \\
\hline 0.05462 & 0.8972 & +1 \\
\hline 0.05871 & 0.8979 & +6 \\
\hline \multicolumn{3}{|c|}{ Polymer: PMMA/Monomer:ST } \\
\hline 0.00 & $0.8885_{9}$ & 0 \\
\hline 0.01165 & 0.8915 & -1 \\
\hline 0.01877 & 0.8933 & -1 \\
\hline 0.03859 & 0.8984 & +5 \\
\hline 0.04252 & 0.8994 & +5 \\
\hline 0.04733 & 0.9005 & -8 \\
\hline \multicolumn{3}{|c|}{ Polymer:SM2/Monomer:ST } \\
\hline 0.00 & $0.8885_{9}$ & -2 \\
\hline 0.02219 & 0.8932 & 0 \\
\hline 0.02859 & 0.8946 & -4 \\
\hline 0.04536 & 0.8980 & +7 \\
\hline \multicolumn{3}{|c|}{ Polymer: PST/Monomer: MMA } \\
\hline 0.00 & $0.9207_{1}$ & +1 \\
\hline 0.00811 & 0.9218 & 0 \\
\hline 0.01484 & 0.9227 & -1 \\
\hline 0.02408 & 0.9240 & +3 \\
\hline 0.03348 & 0.9252 & -5 \\
\hline 0.04531 & 0.9269 & +3 \\
\hline 0.05649 & 0.9284 & -1 \\
\hline 0.07598 & 0.9311 & +1 \\
\hline \multicolumn{3}{|c|}{ Polymer: PMMA/Monomer : MMA } \\
\hline 0.00 & $0.9207_{1}$ & +2 \\
\hline 0.01889 & 0.9251 & -1 \\
\hline 0.02789 & 0.9272 & -2 \\
\hline 0.05747 & 0.9343 & +5 \\
\hline 0.06400 & 0.9358 & -2 \\
\hline
\end{tabular}

$$
v=\left(1-w_{\mathrm{p}}\right) v_{\mathrm{j}}+w_{\mathrm{p}} v_{\mathrm{p}, \mathrm{j}}^{\mathrm{app}}
$$

where $v(=1 / \rho)$ is the specific volume of the solution, and $w_{\mathrm{p}}$, the weight fraction of the polymer. Values of $v_{\mathrm{p}, \mathrm{j}}^{\mathrm{app}}$ computed from the data in Tables III and IV are plotted against $w_{\mathrm{p}}$ in Figures 2 and 3 . Although the data points are somewhat scattered, especially at low concentrations, no systematic
Table IV. Densities of two-component solutions ( $p$ CS-MA systems, $40^{\circ} \mathrm{C}$ )

\begin{tabular}{lll}
\hline$w_{\mathrm{p}}$ & $\frac{\rho}{10^{5} \Delta \rho}$ \\
\cline { 2 - 3 } & $\frac{\mathrm{g} \mathrm{ml}^{-1}}{2}$ & \\
\hline
\end{tabular}

Polymer : $\mathrm{P} p \mathrm{CS} /$ Monomer : $p \mathrm{CS}$

$\begin{array}{lll}0.00 & 1.0640_{8} & +2 \\ 0.01625 & 1.0667 & -2 \\ 0.02691 & 1.0685 & +2 \\ 0.03303 & 1.0695 & +1 \\ 0.04133 & 1.0708 & -6 \\ 0.05397 & 1.0730 & +4\end{array}$

Polymer : PMA/Monomer : $p$ CS

$\begin{array}{llr}0.00 & 1.0640_{8} & +2 \\ 0.01364 & 1.0658 & 0 \\ 0.02614 & 1.0674 & +1 \\ 0.03048 & 1.0679 & -5 \\ 0.04385 & 1.0697 & +4\end{array}$

Polymer : CSM2/Monomer : $p$ CS

$\begin{array}{lll}0.00 & 1.0640_{8} & +3 \\ 0.01311 & 1.0661 & -1 \\ 0.02077 & 1.0673 & -1 \\ 0.03379 & 1.0693 & -6 \\ 0.04437 & 1.0711 & +6\end{array}$

Polymer : $\mathrm{P} p \mathrm{CS} /$ Monomer : MA

$\begin{array}{llr}0.00 & 0.9308_{1} & +2 \\ 0.01904 & 0.9355 & 0 \\ 0.04399 & 0.9417 & -7 \\ 0.05773 & 0.9453 & +5\end{array}$

Polymer : PMA/Monomer : MA

$\begin{array}{llr}0.00 & 0.9308_{1} & 0 \\ 0.01311 & 0.9388 & +5 \\ 0.01950 & 0.9351 & -8 \\ 0.02549 & 0.9365 & -4 \\ 0.03160 & 0.9380 & +8 \\ 0.04169 & 0.9402 & -1\end{array}$

Polymer : CSM1/Monomer : MA

$\begin{array}{llr}0.00 & 0.9308_{1} & -1 \\ 0.01272 & 0.9339 & 0 \\ 0.01792 & 0.9352 & +3 \\ 0.02524 & 0.9369 & -5 \\ 0.03283 & 0.9388 & -1 \\ 0.04375 & 0.9415 & +1\end{array}$

trend is apparent in the concentration ranges studied.

Some authors ${ }^{4,5}$ claim that the apparent specific volume may change rather sharply at concentrations below 1 or $2 \%$. Although our measurements were not made at concentrations low enough to comment on this matter, it is unlikely that such a 
phenomenon appears in ordinary systems, or even in our systems. In fact, the data of Schulz and Hoffmann ${ }^{6}$ and those of Horth et al. ${ }^{7}$ indicate that $v_{\mathrm{p}, \mathrm{j}}^{\mathrm{app}}$ is virtually constant below about $2 \%$.

Previously, we proposed the following approximate equation representing the concentration dependence of $v_{\mathrm{p}, \mathrm{j}}^{\mathrm{app}}$ :

$$
v_{\mathbf{p}, \mathbf{j}}^{\mathrm{app}}=\tilde{v}_{\mathrm{p}, \mathrm{j}}^{0}+\left(v_{\mathrm{p}}-\tilde{v}_{\mathrm{p}, \mathrm{j}}^{0}\right) \phi_{\mathrm{p}}
$$

where $\tilde{v}_{\mathrm{p}, \mathrm{j}}^{0}$ is the partial specific volume at zero concentration, $v_{\mathrm{p}}$, the specific volume of the pure

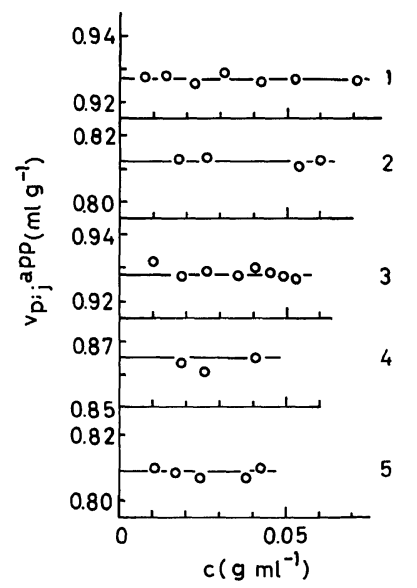

Figure 2. Plots of apparent specific volume $v_{\mathrm{p}, \mathrm{j}}^{\mathrm{app}} v s$. polymer concentration $c$ for polymer(p)/monomer(j) binary mixtures at $40^{\circ} \mathrm{C}$ : (1) PST/MMA, (2) PMMA/ MMA, (3) PST/ST, (4) SM2/ST, (5) PMMA/ST. The solid lines represent the value of $\tilde{v}_{\mathrm{p}, \mathrm{j}}^{0}$ in Table $\mathrm{V}$ (see text). polymer (in the liquid state), and $\phi_{\mathrm{p}}$, the volume fraction of the polymer. Equations 8 was found to fit certain concentrated-solution data fairly well. ${ }^{8}$ Assuming that eq 8 is applicable to our systems, we made an order-of-magnitude estimation of the concentration dependence, and found that $v_{\mathbf{p}, j}^{\text {app }}$ did not change by more than one unit in the third decimal place in the concentration region below $5 \%$. This figure is comparable to the accuracy of the present

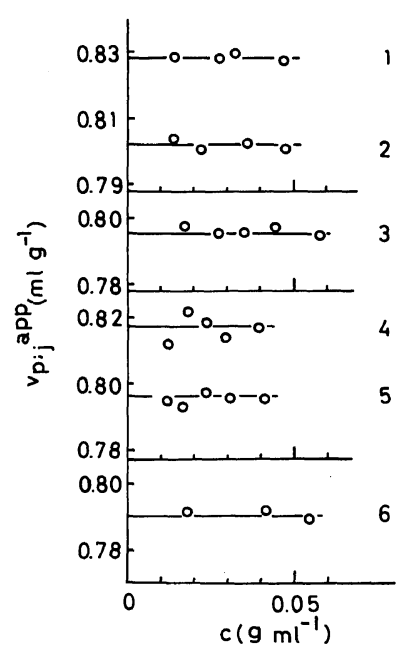

Figure 3. Plots of apparent specific volume $v_{\mathrm{p}, \mathrm{j}}^{\mathrm{app}} v s$. polymer concentration $c$ for polymer(p)/monomer(j) binary mixtures at $40^{\circ} \mathrm{C}$ : (1) PMA $/ p \mathrm{CS}$, (2) $C S M 2 / p C S$, (3) $\mathrm{P} p \mathrm{CS} / p \mathrm{CS}$, (4) PMA/MA, (5) CSM1/MA, (6) $\mathrm{P} p$ CS/MA. The solid lines represent the value of $\tilde{v}_{\mathrm{p}, \mathrm{j}}^{0}$ in Table V (see text).

Table V. Results of least-squares calculations

\begin{tabular}{|c|c|c|c|c|c|}
\hline \multicolumn{2}{|c|}{ System } & \multirow{2}{*}{$\frac{\rho_{\mathrm{j}}}{\mathrm{g} \mathrm{ml}^{-1}}$} & \multirow{2}{*}{$1-v_{\mathrm{p}, \mathrm{j}}^{\mathrm{app}} \rho_{\mathrm{j}}$} & \multirow{2}{*}{$\frac{\tilde{v}_{\mathrm{p}, \mathrm{j}}^{0}}{\mathrm{mlg}^{-1}}$} & \multirow{2}{*}{$\frac{\sigma_{p, j}{ }^{a}}{m l g^{-1}}$} \\
\hline Polymer & Monomer & & & & \\
\hline PST & ST & 0.88857 & 0.17581 & 0.928 & $0.002_{0}$ \\
\hline PMMA & ST & 0.88859 & 0.28139 & 0.809 & $0.001_{7}$ \\
\hline PST & MMA & 0.92070 & 0.14694 & 0.927 & $0.001_{2}$ \\
\hline PMMA & MMA & 0.92069 & 0.25265 & 0.812 & $0.001_{3}$ \\
\hline SM2 & ST & 0.88861 & 0.23145 & 0.865 & $0.003_{1}$ \\
\hline $\mathrm{PpCS}$ & $p \mathrm{CS}$ & 1.06406 & 0.15366 & 0.795 & $0.001_{7}$ \\
\hline PMA & $p \mathrm{CS}$ & 1.06406 & 0.11940 & 0.828 & $0.001_{0}$ \\
\hline $\mathrm{PpCS}$ & MA & 0.93079 & 0.26495 & 0.790 & $0.001_{8}$ \\
\hline PMA & MA & 0.93081 & 0.23991 & 0.817 & $0.003_{9}$ \\
\hline CSM1 & MA & 0.93082 & 0.25910 & 0.796 & $0.001_{9}$ \\
\hline CSM2 & $p \mathrm{CS}$ & 1.06405 & 0.14709 & 0.802 & $0.001_{9}$ \\
\hline
\end{tabular}

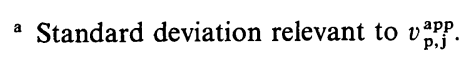


measurements, and the data presented in Figures 2 and 3 are not in conflict with this prediction. Some literature data ${ }^{6,8-12}$ also show that the concentration dependence of the apparent specific volume is negligible in this concentration range.

In order to obtain statistically well-defined values of $\tilde{v}_{\mathrm{p}, \mathrm{j}}^{0}$, the density data in Tables III and IV were fitted, by the least-squares method, to the following relation, ${ }^{9,10}$ which is equivalent to eq 7 :

$$
\rho=\rho_{\mathrm{j}}+\left(1-v_{\mathrm{p}, \mathrm{j}}^{\mathrm{app}} \rho_{\mathrm{j}}\right) c
$$

where $c\left(=\rho w_{\mathrm{p}}\right)$ is the polymer concentration in $\mathrm{g} \mathrm{ml}^{-1}$, and $\rho_{\mathrm{j}}$ and $\left(1-v_{\mathrm{p}, \mathrm{j}}^{\mathrm{app}} \rho_{\mathrm{j}}\right)$ are regarded as constant parameters. The results are listed in Table V. In Tables III and IV, we give the differences $\Delta \rho$

$$
\Delta \rho=\rho-\rho_{\text {cal }}
$$

where $\rho$ is the observed density, and $\rho_{\text {cal }}$, the density computed from eq 9 using the least-squares values of $\rho_{\mathrm{j}}$ and $\left(1-v_{\mathrm{p}, \mathrm{j}}^{\mathrm{app}} \rho_{\mathrm{j}}\right)$. The tables show that $\Delta \rho$ is of the order of $10^{-5}$ and exhibits no systematic trend. This confirms again that in the concentration ranges examined, $v_{\mathrm{p}, \mathrm{j}}^{\mathrm{app}}$ may be regarded as constant and equal to $\tilde{v}_{\mathrm{p}, \mathrm{j}}^{0}$ within experimental accuracy. In Table $\mathrm{V}, \tilde{v}_{\mathrm{p}, \mathrm{j}}^{0}$ thus determined are presented along with standard deviation $\sigma_{\mathrm{p}, \mathrm{j}}$ estimated from

$$
\sigma_{\mathrm{p}, \mathrm{j}}^{2}=(n-1)^{-1} \sum^{n}\left(v_{\mathrm{p}, \mathrm{j}}^{\mathrm{app}}-\tilde{v}_{\mathrm{p}, \mathrm{j}}^{0}\right)^{2}
$$

where $v_{\mathrm{p}, \mathrm{j}}^{\mathrm{app}}$ refers to the individual data points in Figures 2 and 3, and $n$ is the number of data points.

\section{Excess Volume Parameter $\Delta V_{12}$}

Usually, the molecular volume of a copolymer (per monomeric unit) can not be represented by the composition average of those of the parent polymers, owing to the presence of alternating chemical bonds. ${ }^{13,14}$ The parameter $\Delta V_{12}$ in eq 1 and 2 takes account of this fact. For a polymer(p)/ monomer(j) binary mixture, eq 1 reads

$$
\tilde{V}_{\mathrm{p}, \mathrm{j}}^{0}=F_{1} \tilde{V}_{1, \mathrm{j}}^{0}+F_{2} \tilde{V}_{2, \mathrm{j}}^{0}+F_{12} \Delta V_{12}
$$

To a first-order approximation, $\Delta V_{12}$ is a constant, independent of the solvent. ${ }^{1}$ Insofar as the terminalmodel kinetics of copolymerization is valid,,$^{2,15-17}$ the population $F_{12}$ of alternating bonds may be calculated from ${ }^{18}$

$$
F_{12}=\frac{4 F_{1} F_{2}}{1+\left[1+4 F_{1} F_{2}\left(r_{1} r_{2}-1\right)\right]^{1 / 2}}
$$

where $r_{1}$ and $r_{2}$ are the reactivity ratios. Strictly speaking, eq 13 is correct for instantaneous copolymers. However, since our samples are prepared at relatively low conversions (see Table II), eq 13 should be a useful approximation for the present purpose.

The reactivity ratio values were recently evaluated to be $r_{1}=0.523$ and $r_{2}=0.460$ for the ST(1)$\operatorname{MMA}(2)$ system, ${ }^{19}$ and $r_{1}=1.21$ and $r_{2}=0.144$ for the $p \mathrm{CS}(1)-\mathrm{MA}(2)$ system. ${ }^{2}$ (We previously showed that the $p$ CS-MA system is better represented by the penultimate model. ${ }^{2}$ For the present purpose, however, the terminal model with the above parameter values is sufficiently accurate.) Based on the $\tilde{v}_{\mathrm{p}}^{0}$ data in Table $\mathrm{V}$, we found that $\Delta V_{12}=$ $-1.42 \mathrm{ml} \mathrm{mol}^{-1}$ for the ST-MMA system, and $\Delta V_{12}=-0.37 \mathrm{ml} \mathrm{mol}^{-1}$ for the $p \mathrm{CS}-\mathrm{MA}$ system. These values are rather small. In contrast, relatively large values of $\Delta V_{12}$ have been reported for the vinyl acetate (VA)-vinyl chloride (VC) ${ }^{20}$ and ethyl acetate (EA)-MMA ${ }^{21}$ systems. It is of interest that $\Delta V_{12}$ is negative for the ST-MMA, $p \mathrm{CS}$ $\mathrm{MA}$ and VA-VC copolymers, but positive for the EA-MMA copolymer.

\section{Comparison with Theory}

Table VI gives all the parameter values necessary to compute $\tilde{V}_{\mathrm{p}}^{0}$ and $\Gamma^{0}$ using eq 1 and 2 , respectively. In order to check the validity of eq 1 , density measurements were made on several STMMA and $p$ CS-MA copolymers in mixtures of the

Table VI. List of parameter values ${ }^{\mathrm{a}}$

\begin{tabular}{lcc}
\hline Parameter & ST-MMA & $p$ CS-MA \\
\hline$r_{1}$ & 0.523 & 1.21 \\
$r_{2}$ & 0.460 & 0.144 \\
$V_{3}$ & 117.04 & 130.16 \\
$V_{4}$ & 108.61 & 92.39 \\
$\tilde{V}^{0}{ }_{1,3}$ & 96.51 & 110.11 \\
$\tilde{V}_{1,4}^{0}$ & 96.41 & 109.42 \\
$\tilde{V}_{2,3}^{0}$ & 80.90 & 71.21 \\
$\tilde{V}_{2,4}^{0}$ & 81.20 & 70.26 \\
$\Delta V_{12}$ & -1.42 & -0.37 \\
$10^{3} A_{0}{ }^{\mathrm{b}}$ & -2.9 & -3.5 \\
$10^{3} A_{1}{ }^{\mathrm{b}}$ & -3.2 & 0 \\
\hline
\end{tabular}

a Components 1, 2, 3 and 4 are PST (PpCS), PMMA (PMA), ST ( $p$ CS) and MMA (MA) respectively; $V$ 's and $\Delta V_{12}$ are in $\mathrm{ml} \mathrm{mol}^{-1}$.

b $a_{34}=A_{0}+A_{1}\left(x_{3}-x_{4}\right)$. 
Table VII. Comparison between observed and calculative values of partial molar volume $\tilde{V}_{\mathrm{p}}^{0}$ of the ST-MMA and $p$ CS-MA copolymers in mixtures of the relevant monomers $\left(40^{\circ} \mathrm{C}\right)$

\begin{tabular}{|c|c|c|c|c|c|c|}
\hline \multicolumn{3}{|c|}{ System } & \multirow{2}{*}{$x_{3}{ }^{\mathrm{a}}$} & \multirow{2}{*}{$w_{\mathrm{p}}{ }^{\mathrm{b}}$} & \multirow{2}{*}{$\tilde{V}_{\text {pobs }}^{0}$} & \multirow{2}{*}{$\tilde{V}_{\text {pcal }}^{0}$} \\
\hline Copolymer & Monomer (3) & Monomer (4) & & & & \\
\hline \multirow[t]{2}{*}{ SMl } & \multirow[t]{2}{*}{$\mathrm{ST}$} & \multirow[t]{2}{*}{ MMA } & \multirow[t]{2}{*}{0.20211} & 0.03348 & $84.4_{2}$ & \multirow[t]{2}{*}{84.54} \\
\hline & & & & 0.04863 & $84.4_{5}$ & \\
\hline \multirow[t]{2}{*}{ SM2 } & \multirow[t]{2}{*}{$\mathrm{ST}$} & \multirow[t]{2}{*}{ MMA } & \multirow[t]{2}{*}{0.56762} & 0.02977 & $88.5_{8}$ & \multirow[t]{2}{*}{88.53} \\
\hline & & & & 0.04449 & $88.9_{1}$ & \\
\hline \multirow[t]{2}{*}{ SM3 } & \multirow[t]{2}{*}{ ST } & \multirow[t]{2}{*}{ MMA } & \multirow[t]{2}{*}{0.80247} & 0.02388 & $91.8_{5}$ & \multirow[t]{2}{*}{91.63} \\
\hline & & & & 0.02991 & $92.0_{2}$ & \\
\hline \multirow[t]{2}{*}{ CSM1 } & \multirow[t]{2}{*}{$p \mathrm{CS}$} & \multirow[t]{2}{*}{ MA } & 0.30854 & 0.02120 & $90.0_{8}$ & 90.52 \\
\hline & & & 0.33023 & 0.03013 & $90.2_{5}$ & 90.54 \\
\hline \multirow[t]{2}{*}{ CSM2 } & \multirow[t]{2}{*}{$p \mathrm{CS}$} & \multirow[t]{2}{*}{ MA } & 0.58842 & 0.02957 & $96.9_{5}$ & 97.21 \\
\hline & & & 0.60580 & 0.01973 & $97.0_{8}$ & 97.23 \\
\hline \multirow[t]{2}{*}{ CSM3 } & \multirow[t]{2}{*}{$p \mathrm{CS}$} & \multirow[t]{2}{*}{ MA } & 0.78231 & 0.02982 & $102.2_{4}^{\circ}$ & 102.80 \\
\hline & & & 0.80152 & 0.01968 & $102.6_{0}$ & 102.82 \\
\hline
\end{tabular}

a Volume fraction of monomer 3: $x_{3}=1-x_{4}$.

b Weight concentration of polymer at which the density measurements were made.

c Value based on the apparent specific volume determined at concentration $w_{\mathrm{p}}$ (see text).

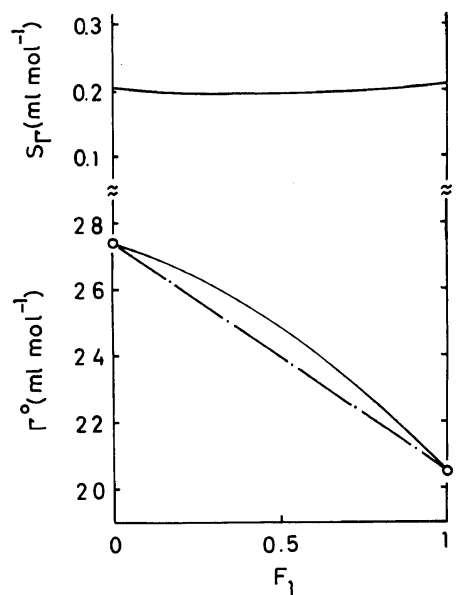

Figure 4. Plot of contraction factor $\Gamma^{0} v s$. copolymer mole-composition $F_{1}$ for incipient bulk-copolymerization of $\mathrm{ST}(1)-\mathrm{MMA}(2)$ at $40^{\circ} \mathrm{C}$, as calculated in this work (full curve): the uppermost curve represents an estimate of the standard deviation $S_{\Gamma}$. The dot-dash line represents the linear combination theory.

relevant monomers. The weight fractions $w_{\mathrm{p}}$ used for these measurements were so low (below $5 \%$, in all cases) that, following the above arguments, $v_{\mathrm{p}}^{\text {app }}$ was set equal to $\tilde{v}_{\mathrm{p}}{ }^{0}$. The values of partial molar volume $\tilde{V}_{\mathrm{p}}^{0}$ thus determined are compared with the

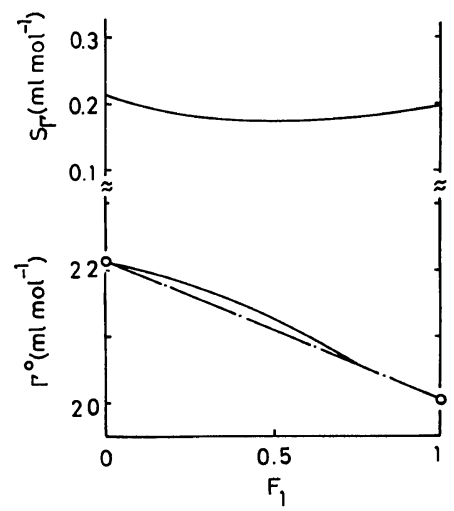

Figure 5. Plot of contraction factor $\Gamma^{0} v s$. copolymer mole composition $F_{1}$ for incipient bulk-copolymerization of $p \mathrm{CS}(1)-\mathrm{MA}(2)$ at $40^{\circ} \mathrm{C}$, as calculated in this work (full curve): the uppermost curve represents an estimate of the standard deviation $S_{\Gamma}$. The dot-dash line represents the linear combination theory.

calculated values in Table VII. For both ST-MMA and $p$ CS-MA systems, the agreement is satisfactory.

\section{Computation of the Contraction Factor}

Figures 4 and 5 present numerical values of the contraction factor $\Gamma^{0}$ computed from eq 2 . For 


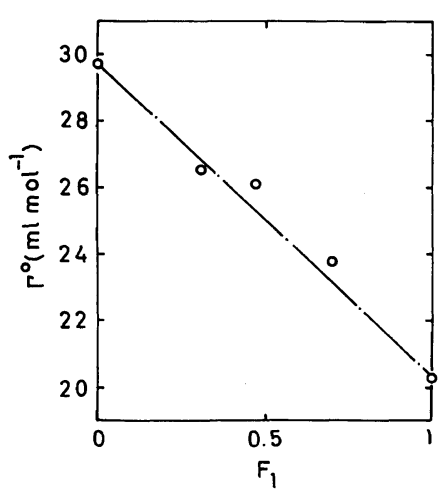

Figure 6. Plot of contraction factor $\Gamma^{0} v s$. copolymer mole-composition $F_{1}$ for incipient bulk-copolymerization of ST(1)-MMA(2) at $60^{\circ} \mathrm{C}$, reported by Braun and Disselhoff ${ }^{22}$ (circles). The dot-dash line represents the linear combination theory.

both ST-MMA and $p$ CS-MA systems, $\Gamma^{0}$ exhibits positive deviations from the linear combination of $\Gamma_{1}{ }^{0}$ and $\Gamma_{2}{ }^{0}$ (shown by the dot-dash lines in the figures.) In this connection, we cite in Figure 6 the data of Braun and Disselhoff, ${ }^{22}$ who determined $\Gamma^{0}$ for ST-MMA bulk copolymerization at $60^{\circ} \mathrm{C}$ by measuring volume vs. conversion curves. Although their results cannot be directly compared with ours because of the temperature difference, their $\Gamma^{0}$ values do exhibit a similar trend.

We now consider the accuracy of our $\Gamma^{0}$ values. Since the main errors in $\Gamma^{0}$ are in the determination of $\tilde{V}^{0}$, it may suffice to consider the latter only. According to one standard theory, an approximate estimate of the variance $S_{\Gamma}^{2}$ relevant to $\Gamma^{0}$ can be made by the relation

$$
\begin{aligned}
S_{\Gamma}^{2}= & F_{1}^{2} S_{1,3}^{2}+F_{2}{ }^{2} S_{2,4}^{2} \\
& +\left(S_{\mathrm{p}, \mathrm{j}}^{2}+F_{1}{ }^{2} S_{1, \mathrm{j}}^{2}+F_{2}{ }^{2} S_{2, \mathrm{j}}^{2}\right) / r \\
& +\left(x_{3} F_{3}\right)^{2}\left(S_{1,3}^{2}+S_{1,4}^{2}\right) \\
& +\left(x_{4} F_{1}\right)^{2}\left(S_{2,4}^{2}+S_{2,3}^{2}\right)
\end{aligned}
$$

where $S_{\mathrm{p}, \mathrm{j}}^{2}$ is the variance of $\tilde{V}_{\mathrm{p}, \mathrm{j}}^{0}$, and $r$, the number of measurements carried out to determined $\Delta V_{12}$ (see eq 2, 3 and 12). Based on the values of $\sigma_{\mathrm{p}, \mathrm{j}}$ listed in Table $\mathrm{V}$, we computed $S_{\Gamma}^{2}$ as a function of $F_{1}$ (Figures 4 and 5). The results show that in no case does the standard deviation $S_{\Gamma}$ exceed $1 \%$ of $\Gamma^{0}$. This figure can be used as a measure for the accuracy of our $\Gamma^{0}$ values.
In any case, the deviations exhibited in Figures 4 to 6 from the linear combination theory are not very large. However, this by no means warrants the general validity of the linear combination theory. In our particular systems, the values of $a_{34}$ and $\Delta V_{12}$ as well as the difference $\tilde{V}_{\mathrm{i}, 3}^{0}-\tilde{V}_{\mathrm{i}, 4}^{0}$ happened to be rather small. This explains why the linear combination held as a reasonable approximation. Looking to the literature, we find rather numerous examples in which $a_{34}{ }^{1,3}$ and $\Delta V_{12}{ }^{20,21}$ are quite large and the solvent dependence of $\tilde{V}_{\mathrm{i}}^{0}$ is significant. ${ }^{3,6,23,24}$ Equation 2 shows that the linear combination theory may result in considerable error, if one or more of the parameter values in a given system are large. A few such systems have been illustrated in Figures 2 and 3 of ref 1 . We also note that these arguments are concerned not only with copolymerization but also with the homopolymerization carried out in a mixture of a monomer and solvent(s) (see eq 2), and emphasize that no optimistic view should be taken in predicting the contraction factor.

\section{REFERENCES}

1. T. Fukuda, Y.-D. Ma, M. Nagata, and H. Inagaki, Polym. J., 14, 729 (1982).

2. T. Fukuda, Y.-D. Ma, and H. Inagaki, Polym. J., 14, 705 (1982).

3. T. M. Aminabhavi and P. Munk, Macromolecules, 12, 1186 (1979).

4. B. Rosen, J. Polym. Sci., 17, 559 (1955).

5. W. Heller and A. C. Thompson, J. Colloid Sci., 6, 57 (1951).

6. G. V. Schulz and M. Hoffmann, Makromol. Chem., 23, 220 (1957).

7. A. Horth, D. Patterson, and M. Rinfret, J. Polym. Sci., 39, 189 (1959).

8. T. Fukuda, M. Nagata, Y.-D. Ma, and H. Inagaki, Polym. Prepr. Jpn., 31, 2153 (1982).

9. M. Griffel, R. S. Jessup, J. A. Cogliano, and R. P. Park, J. Res. Natl. Bur. Stand., 52, 217 (1954).

10. B. Trathnigg, Makromol. Chem., 181, 1979 (1980).

11. J. Francois and F. Candau, Eur. Polym. J., 9, 1355 (1973).

12. Th. G. Scholte, J. Polym. Sci., A-2, 8, 841 (1970).

13. H. Inagaki, Makromol. Chem., 75, 217 (1964).

14. A. Nakazawa, Y. Murakami, T. Kotaka, and H. Inagaki, Bull. Inst. Chem. Res., Kyoto Univ., 53, 387 (1975).

15. F. Tüdös, T. Kelen, and T. F. Berezhnikh, J. Polym. Sci., Polym. Symp., 50, 109 (1975).

16. J. A. Seiner and M. Litt, Macromolecules, 4, 308 


\section{Contraction Factors for Some Copolymerizations}

(1971).

17. M. Kamachi, Adv. Polym. Sci., 38, 56 (1981).

18. H. J. Harwood and W. M. Ritckey, J. Polym. Sci., B, 2, 601 (1964).

19. Y.-D. Ma, T. Fukuda, and H. Inagaki, to be published.

20. A. Nakajima, H. Sotobayashi, and I. Sakurada, Kobunshi Kagaku, 14, 566 (1957).
21. W. Mächtle and H. Fischer, Angew. Makromol. Chem., 7, 147 (1969).

22. D. Braun and G. Disselhoff, Polymer, 18, 963 (1977).

23. G. G. Cameron and J. Cameron, Polymer, 14, 107 (1973).

24. D. J. Streeter and R. F. Boyer, Ind. Eng. Chem., 43, 1970 (1951). 